Check for updates

Cite this: Environ. Sci.: Processes Impacts, 2020, 22, 1095

\title{
Correction: Organic contaminants of emerging concern in Norwegian digestates from biogas production
}

\author{
Aasim M. Ali, ${ }^{\text {aa }}$ Astrid S. Nesse, ${ }^{\mathrm{b}}$ Susanne Eich-Greatorex, ${ }^{\mathrm{b}}$ Trine A. Sogn, ${ }^{\mathrm{b}}$ \\ Stine G. Aanrud, ${ }^{C}$ John A. Aasen Bunæs, ${ }^{C}$ Jan L. Lyche ${ }^{c}$ and Roland Kallenborn ${ }^{\text {acd }}$
}

DOI: $10.1039 / \mathrm{d} 0 \mathrm{em} 90012 \mathrm{e}$

rsc.li/espi

Correction for 'Organic contaminants of emerging concern in Norwegian digestates from biogas production' by Aasim M. Ali et al., Environ. Sci.: Processes Impacts, 2019, 21, 1498-1508.

After revisiting and evaluating the data of our recent publication "Organic contaminants of emerging concern in Norwegian digestates from biogas production", we identified several minor erroneous details in Table 1 which need to be corrected in order to allow correct interpretation of the results. In Table 1, the operating conditions of the biogas processes are listed according to information from the respective biogas plants. An updated version of Table 1 is included here, as well as amendments to sections as corrections of the earlier assumptions.

\section{Corrections}

p. 1499 Materials and methods - Biogas process conditions

Original interpretation: "The sample set also included one liquid sample $\left(I_{\text {sub }}\right)$ and a liquid digestate sample $\left(I_{\text {dig }}\right)$ from an experimental biogas reactor associated with plant I. Biogas plant I uses $20 \%$ sludge from young fish and $80 \%$ manure as a raw substrate (Table 1)."

Correction: Biogas plant I and the experimental biogas reactor are two separate reactors with different operating conditions, but are listed as one reactor in the original paper. The experimental reactor is now added to the modified Table 1 (named $\mathrm{I}_{\mathrm{ExP}}$ in Table 1). $\mathrm{I}_{\mathrm{EXP}}$ uses $20 \%$ sludge from young fish and $80 \%$ manure as a substrate, while biogas plant I uses $72 \%$ sewage sludge and $28 \%$ food waste as substrate.

Corrected text: "The sample set also included one liquid sample $\left(I_{\text {sub }}\right)$ and a liquid digestate sample $\left(I_{\text {dig }}\right)$ from an experimental biogas reactor $\mathrm{I}_{\mathrm{EXP}}$, associated with plant $\mathrm{I}$. This experimental biogas plant $\mathrm{I}_{\mathrm{EXP}}$ uses $20 \%$ sludge from young fish and $80 \%$ manure as a raw substrate (Table 1)."

p. 1500 Results and discussion - Substrate composition

Original interpretation: "High levels of octocrylene (a sun-screen ingredient), in some cases exceeding the uLOQ method limit, were found almost exclusively when sewage sludge was used for biogas production."

Correction: Elevated levels of octocrylene were found across all investigated biogas digestates produced from food waste, in amounts which are comparable to the concentrations found in those produced from sewage sludge. In $E_{(\mathrm{S})}$ (solid digestate from

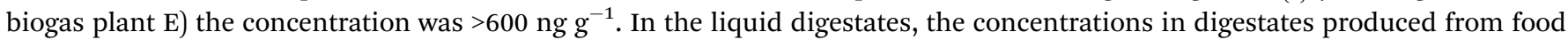
waste were $25.8 \mathrm{ng} \mathrm{g}^{-1}$ (plant L), $224 \mathrm{ng} \mathrm{g}^{-1}$ (plant E), and $44.8 \mathrm{ng} \mathrm{g}^{-1}$ (plant G).

Corrected text: "High levels of octocrylene (a sunscreen ingredient), in some cases exceeding the uLOQ method limit, were found in food waste and sewage sludge-based biogas digestates."

p. 1500 Results and discussion - Substrate composition

Original interpretation: "The correlation calculations revealed a significant positive correlation between the CEC level and the use of thermal hydrolysis (PTTHP) in the pre-treatment of the substrate prior to AD as well as the dry-matter content (\% DM)."

Correction: The correlation analysis was repeated with the updated information from Table 1. PTTHP still has a positive correlation with the CEC level, but this corrected correlation is not significant, whereas the correlation between CEC level and dry matter is still significant.

\footnotetext{
${ }^{a}$ Faculty of Chemistry, Biotechnology and Food Science (KBM), Norwegian University of Life Sciences (NMBU), NO-1432 Aas, Norway. E-mail: aasimali@nmbu.no ${ }^{b}$ Faculty of Environmental Sciences and Natural Resource Management (MiNa), Norwegian University of Life Sciences (NMBU), NO-1432 Aas, Norway

${ }^{c}$ Faculty of Veterinary Medicine (VetFak), Norwegian University of Life Sciences (NMBU), NO-0454 Oslo, Norway

${ }^{d}$ University Centre in Svalbard, Arctic Technology, NO-9171 Longyearbyen, Svalbard, Norway
} 


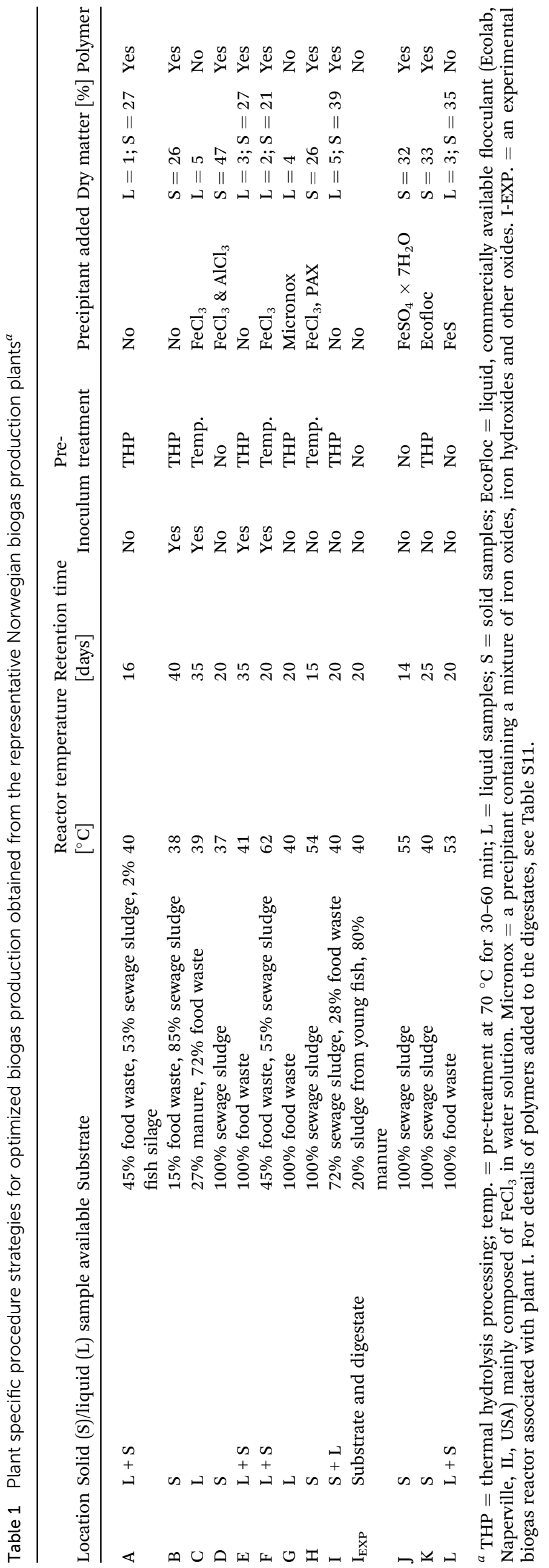


Corrected text: "The correlation calculations revealed a significant positive correlation between the CEC level and the dry-matter content (\% DM)."

p. 1501 Results and discussion - Biogas production and processing

Original interpretation: "The results presented in Fig. 1 indicate that the careful selection of substrate composition (including dry matter content) and optimised conditioning strategies for biogas production may be considered a first important step to reduce the occurrence of potential CECs in the digestate."

Corrected text: "The results presented in Fig. 1 indicate that the careful selection of substrate composition and optimised conditioning strategies for biogas production may be considered a first important step to reduce the occurrence of potential CECs in the digestate."

p. 1503 Results and discussion - Contaminants of emerging concern in liquid digestates

Original interpretation: "Ibuprofen was detected in two liquid biogas digestates mainly derived from sewage sludge based substrates $\left(E_{(\mathrm{L})}\right)$ and $\left.A_{(\mathrm{L})}\right)$ at concentrations of $36 \mu \mathrm{g} \mathrm{L} \mathrm{L}^{-1}$ and $26.7 \mu \mathrm{g} \mathrm{L}^{-1}$, respectively."

Correction: The liquid biogas digestate $E_{(\mathrm{L})}$ is produced from food waste.

Corrected text: "Ibuprofen was detected in two liquid biogas digestates derived from food waste alone or in combination with sewage sludge as substrates, i.e. $E_{(\mathrm{L})}$ and $A_{(\mathrm{L})}$, at concentrations of $36 \mu \mathrm{g} \mathrm{L} \mathrm{L}^{-1}$ and $26.7 \mu \mathrm{g} \mathrm{L}^{-1}$, respectively."

The Royal Society of Chemistry apologises for these errors and any consequent inconvenience to authors and readers. 